\title{
Development of an energy efficient train traffic control system for saving electricity
}

\author{
M. Miyoshi ${ }^{1}$, T. Takeba ${ }^{1} \&$ M. Miyatake ${ }^{2}$ \\ ${ }^{1}$ Railway Systems Engineering Department, Railway Systems Division, \\ Toshiba Corporation, Japan \\ ${ }^{2}$ Department of Engineering and Applied Sciences, \\ Faculty of Science and Technology, Sophia University, Japan
}

\begin{abstract}
Although rail transportation is conventionally considered to be environmentallyfriendly, currently research is being carried out globally to find ways to improve energy-saving in rail transportation. Development of an energy management system for railways and new transport systems including the BRT (Bus Rapid Transit) system has begun. The railway energy management system manages and controls the use of energy for transportation as well as train operation.

An EE (energy efficient) train traffic control system is being developed in order to reduce energy consumption in train traffic operation. This system is mainly useful for urban railways. The control system reduces consumed running energy by assigning several seconds of the scheduled margin times at platforms to inter-stations. While taking care about delay of the trains, the control system adjusts the arrival-and-departure time at stations without making passenger aware of the difference from the usual.

The following methods can be considered in utilization; 1) drivers judge and lengthen the running time appropriately according to the train operation condition of routes; 2) the ground operation control device grasps train traffic conditions and decides the arrival time at the next station and then orders the time to each train using a ground-vehicle transmission system, while drivers operate according to the guidance by the on-board driving assistance equipment; 3 ) trains run with automatic train operation equipment according to the order from the ground operation control device.

By computer simulation for typical urban transport lines, the evaluation of an EE train traffic control algorithm was carried out. As a result, it was confirmed
\end{abstract}


that a $5 \%$ reduction of energy consumed is expected by assigning 5 seconds on average to the margin included in station stoppage time to the running time between stations.

Keywords: energy management, train traffic control, margin times, adjustment of departure and arrival time, driving assistance, ATO (Automatic Train Operation), computer simulation.

\section{Introduction}

Because the transport capacity of the railway per input energy is large and the regenerative energy during braking is useful, the railway system is called an energy-efficient transport system. However, also in the railway system, economizing energy farther and making it more efficient are demanded for the realization of a low carbon society.

In order to reduce energy consumed, the energy reduction of the drive of vehicles is effective, but it is also possible by devising the operating style of trains. The optimization of operation style of a vehicle was studied to reduce energy consumed by using coasting abundantly in the run between stations [1]. Moreover, a research which plans energy reduction by adjusting operation of two or more trains is also advanced such as the CATO system [2].

Aiming at stable transportation, priority is given to the train operation over the electric power supply in the many present Japanese passenger railway systems. Therefore, each member of staff of railway companies, such as electric power, vehicle, traffic management, and vehicle operation departments try to save energy making effort to try to find the best way to manage the railway systems. But there are problems as follows;

(1) The power and energy are decided according to the situation at that time.

(2) There are some cases when peak power becomes large.

(3) Because operations are based on experience, there is room for improvement in the viewpoint of energy saving in both the operation and electric power supply sides in the case of time schedule disorder occurring. That is, since power consumption is not managed, it is thought that power consumption in train operation has room for reduction.

For this reason, the "railway energy management system" has been developed [3]. This system aims at consolidating harmony of transportation and energy consumption for transportation. First, it sets up the desired value of energy consumed for planned traffic and it cooperates and controls train operation and power supply at substations; keeping a timetable.

As part of that, an "EE train traffic control" has been advocated [4]. It controls the operation of trains automatically, in order to control the total operating energy to a planned value, in the range from which an operation timetable is maintained.

In this paper the train operation control system which reduces the energy consumed positively without the change of running time being noticed by the railway user and effects evaluation by a computer simulation are described. 


\section{Energy management system for railway system}

In a general power network, construction of the smart grid is advanced and introduction of renewable power sources and practical use of information and communication technology are remarkable.

The Railway Energy Management System (Railway EMS) aims at realizing harmony of transportation and transportation energy. The concept of the Railway EMS is based on the visualization of electric power. It makes an energy use plan and controls both the operation and electric power supply of trains corporately under the plan. Moreover, it is realizing an energy cycle type railway system by the effective use of regenerating electric power and renewable power sources.

Fig. 1 shows the Railway EMS focusing on train operation.

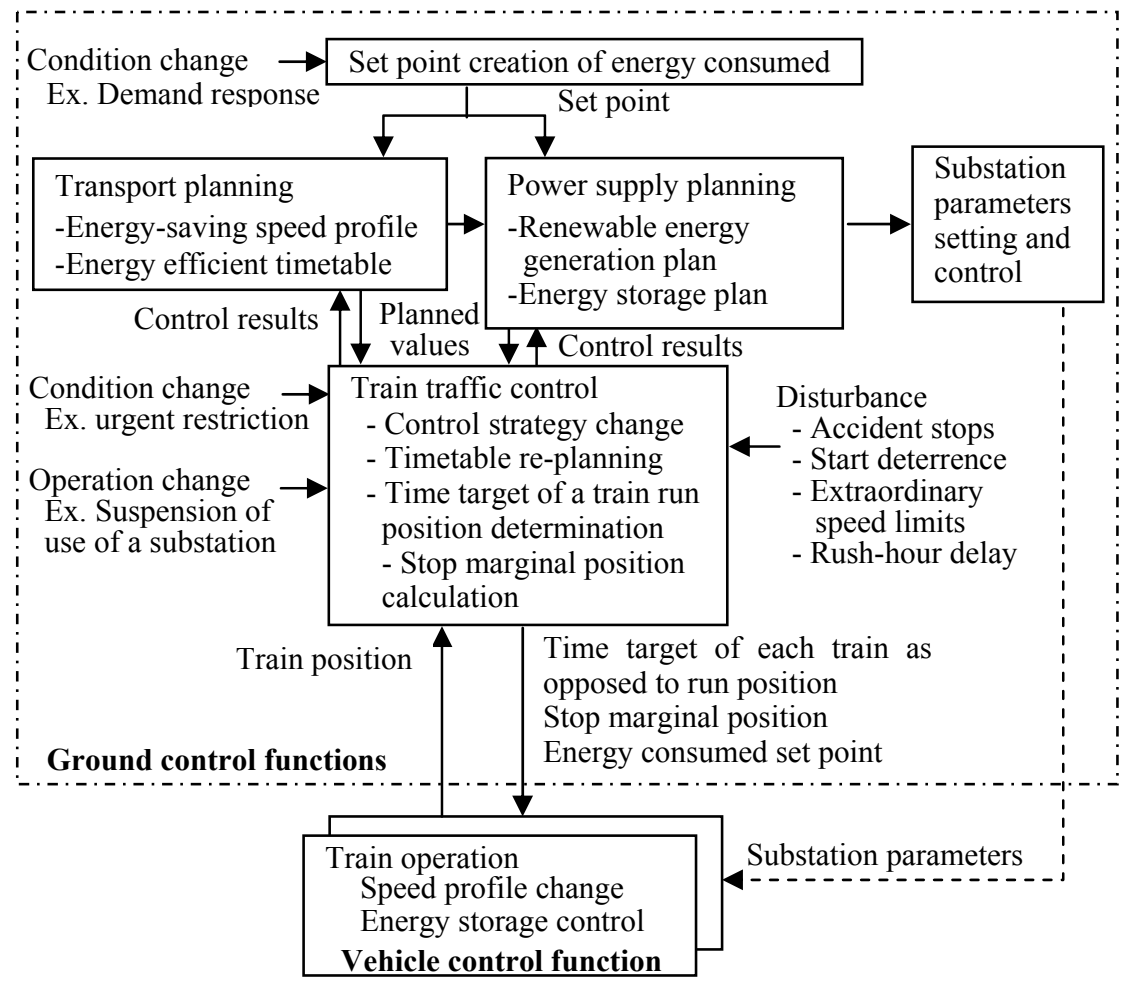

Figure 1: Railway Energy Management System.

First, fully in consideration of premised route conditions, vehicle performance and substation equipment, it decides upon a run curve, operation diagram and the operation composition of power supply system, optimal for both sides of transportation and energy. And based on such demand response information, the preset value of power consumption is improved and is reflected in a transportation plan and a power supply plan if needed. Train traffic control 
function control operation of each train to a daily change of preset value and operation and everyday disturbance, paying attention to energy consumption. On the train side, it carries out in the form of the presentation of operation information or driving assistance information to a driver, and aims at energy saving. In that case, economizing energy in the range permissible for a railway user is carried out positively. At the present time, train traffic control function controls are based on the transportation plan.

In the case of sudden power urgent restriction or the power supply stop, a new transportation plan is made in consideration of energy consumed, and control is carried out by it. The time target to a run position like estimated time of arrival is given to each train with an energy-consumed desired value. Each train aims at whole energy saving by performing the operation which meets the desired value as much as possible in vehicle performance or operation restrictions. EE train traffic control which is described in the next paragraph is one of the methods.

The first of the step of the railway EMS is monitoring which is visualization, and next it is saving in apparatus or at a functional level, and there is a metering depending on the purpose. It ties in with management which eventually cooperates mutually.

\section{EE train traffic control}

The EE traffic control system reduces the running energy positively according to the operation timetable in the range where passengers do not know the change of running time.

\subsection{System configuration}

The system configuration of the EE train traffic control system is shown in Fig. 2.

In this system each train on an operation timetable is controlled. The function of the order to a train will be integrated with the transmission-on ground-vehicle function of the radio train control system in the future.

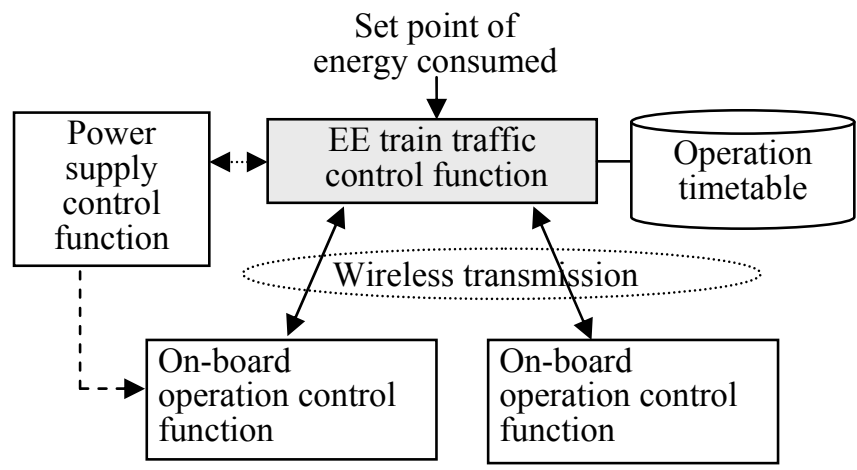

Figure 2: Configuration of EE train traffic control. 


\subsection{Idea of energy reduction of EE train traffic control}

The object system of this control is a city railway. Therefore, as for the interval of a station, it is about from 1 to $2 \mathrm{~km}$. The time required between stations is from 1 to 2 minutes. Stoppage time may be about from 30 second to 1 minute. The view is widely applicable.

Changing the operation control method of train traffic strategically according to the time zone or the confusion situation is useful for energy-saving and stable transportation on a city railway. In rush-hour it should control traffic smoothly without repeating accelerations and decelerations so that it prevents the increase in power consumption. In the off-peak time zone, it should economize energy by utilizing margin time while checking the train traffic situation.

Fig. 3 shows the adjustment method of the arrival-and-departure time for economizing energy in the off-peak time zone. In the case of the above systems, it is checking that the notch-off speed at the time of the run between stations can be reduced, and the power consumption of a train can be reduced by several percent by turning the time by about several seconds which may be taken into consideration by the operation timetable as margin time to the running time between stations [5]. This control system adjusts the arrival-and-departure time in the range where passengers are not conscious of a change of running time, paying attention to this. Moreover, reduction of the run energies of a train is aimed to be in real time, considering that delay by hospitality does not occur.

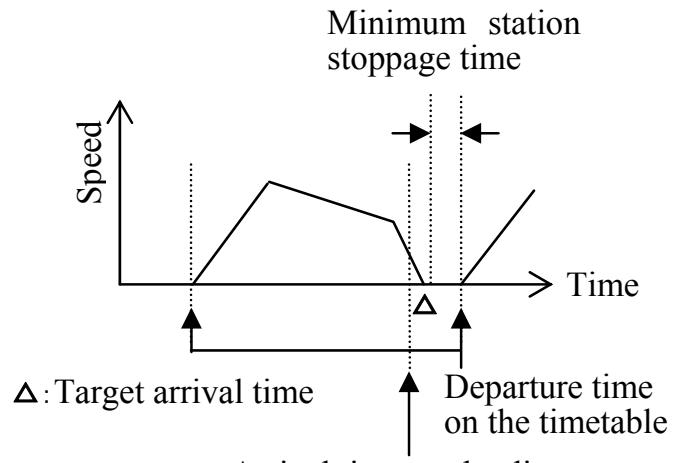

Arrival time on the diagram

Figure 3: Adjustment of arrival-and-departure time.

\subsection{Control flow chart}

The control flow of real-time control is shown in Fig. 4. The operation state of each train is grasped enough, the running time of a train and the hospitality time after arrival are presumed, and it decides on the adjustment time of arrival-anddeparture time so that this control may not induce delay. When schedule control is possible, it is also possible to show a driver adjustment time beforehand and to control train operation. 


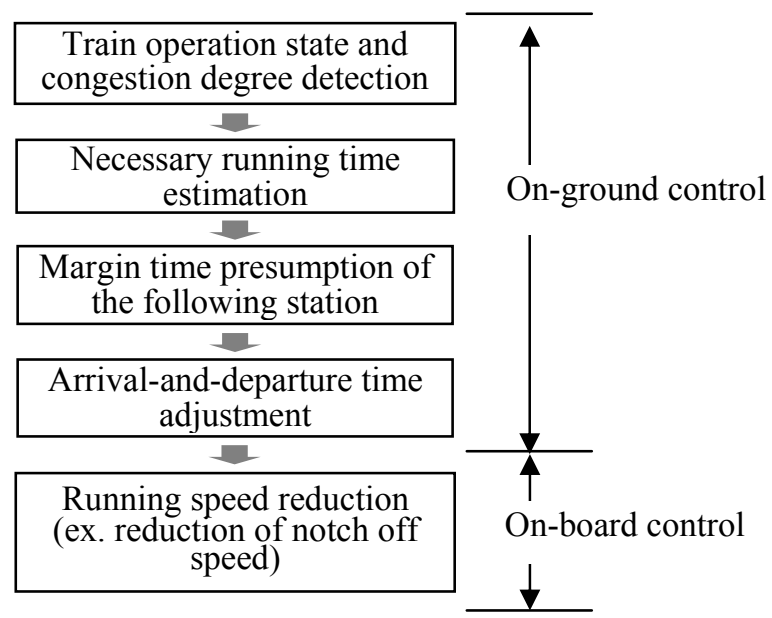

Figure 4: Control flowchart.

\section{Effect evaluation by computation simulation}

In order to evaluate what energy saving can expect to be gained and what the running speed and power consumption between every station may become by EE train traffic control, computer simulation evaluations supposing a real route are carried out. The simulation valuation method is as follows.

\subsection{Simulation valuation method}

In this research, although the railway at large was targeted, in order to improve the concreteness of research, the conditions shown in Table 1 were selected.

Table 1: $\quad$ Simulation conditions.

\begin{tabular}{|c|c|c|c|c|}
\hline Object route & $\begin{array}{c}\text { Length, } \\
\text { the number of } \\
\text { stations }\end{array}$ & $\begin{array}{c}\text { Maximum } \\
\text { speed }[\mathrm{km} / \mathrm{h}]\end{array}$ & $\begin{array}{c}\text { The number of } \\
\text { sub stations }\end{array}$ & $\begin{array}{c}\text { Operation } \\
\text { interval }\end{array}$ \\
\hline $\begin{array}{c}\text { Type A } \\
\text { (Subway) }\end{array}$ & $\begin{array}{c}25 \mathrm{~km}, \\
22 \text { stations }\end{array}$ & 70 & 12 & 4-minute head \\
\hline $\begin{array}{c}\text { Type B } \\
\text { (Commuter line) }\end{array}$ & $\begin{array}{c}20 \mathrm{~km}, \\
12 \text { stations }\end{array}$ & 85 & 3 & $\begin{array}{c}10 \text {-minute } \\
\text { head }\end{array}$ \\
\hline
\end{tabular}

Object routes are two types as follows;

a) Type A (subway): operation with off-braking

b) Type B (commuter line): operation without off-brake

The operation interval is determined depending on the route scale. The number of time adjustment seconds of the arrival time is determined from the stoppage time and the hospitality time assumed by the operation diagram for every object route. Since operation of a train was left to the driver, running 
speeds are decided to adjust the arrival time with change of notch-off speed as an operation change intelligible for a driver. Time for a simulation is aimed at offpeak time zone.

Comparison verification of the total of the input electric energy of substations was carried out in the case where the conventional operation system and EE train traffic control of this proposal are applied. By the conventional operation system, operation united at the departure time and the arrival time of the operation timetable is performed. In EE train traffic control, the target arrival time is made late so that it may be shortened in the range which maintains the minimum hospitality time which sets up the following station stop time beforehand. In both cases, the fluctuation of train operation by disturbance is not assumed this time.

\subsection{The outline of the computer simulator}

Fig. 5 shows the functional composition of the computer simulator used.

Operation of a train is imitated by the operation model of a train with models, such as geographical feature conditions, vehicle performance, and electric power supply system. The operation of a train shall be based on the train operation notch set up beforehand to suit the departure time and the target arrival time of a timetable which was set up. The difference in a route is investigated by the amount of cuts in energy consumption obtained by EE train traffic control.

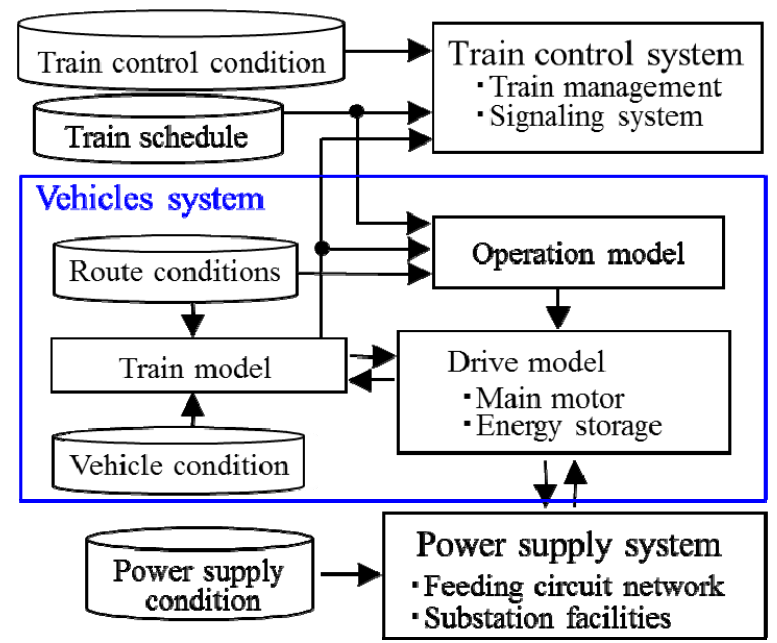

Figure 5: The functional composition of the simulator.

\section{Results}

The simulation result of an EE train traffic control system is shown below in the cases of a subway and a commuter train. 


\subsection{The simulation results of subway}

The simulation results are shown in figs. 6-8. Fig. 6 is a multiple train operation curve (elements on a larger scale). In this proposed control system, it turns out that the influence on an operation diagram can be inhibited. Fig. 7 shows the speed from the starting station of a certain train to a destination station and the transition of power consumption. Fig. 8 shows those enlargements and electric energy. In this example, the arrival adjustment time in each station was an average of 4 seconds, and when this proposed control system was carried out to a down line, total substation input electric energy decreased by $1.7 \%$.

By these, it checked that the effect of economizing energy was expectable by adjustment of arrival and departure time.

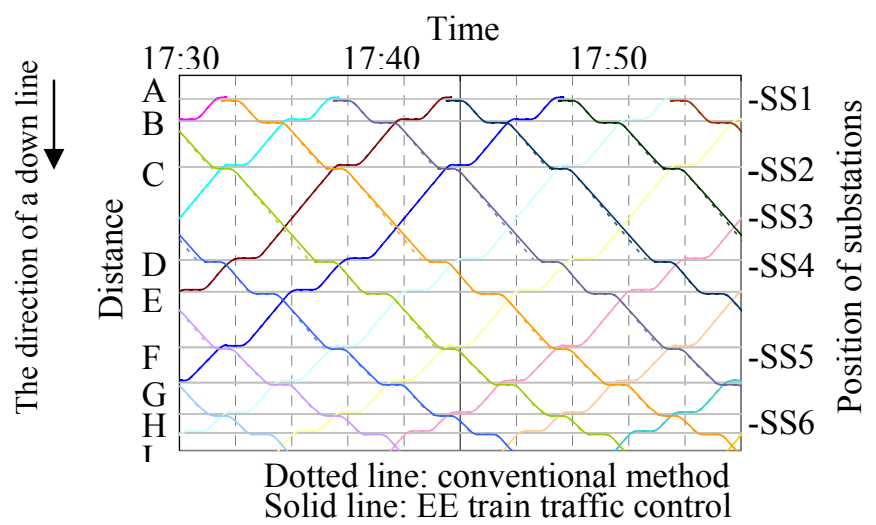

Figure 6: Simulation results (train diagram, elements on a larger scale).

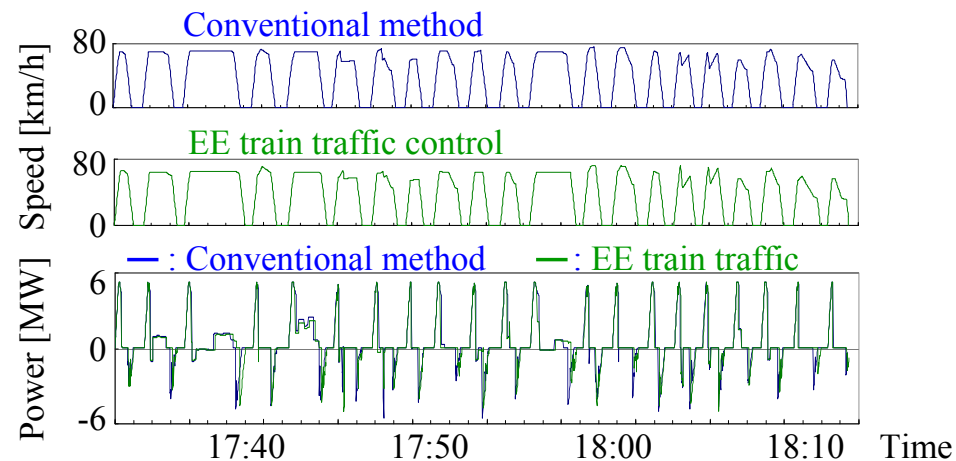

Figure 7: $\quad$ Simulation results (changes of speed and power). 


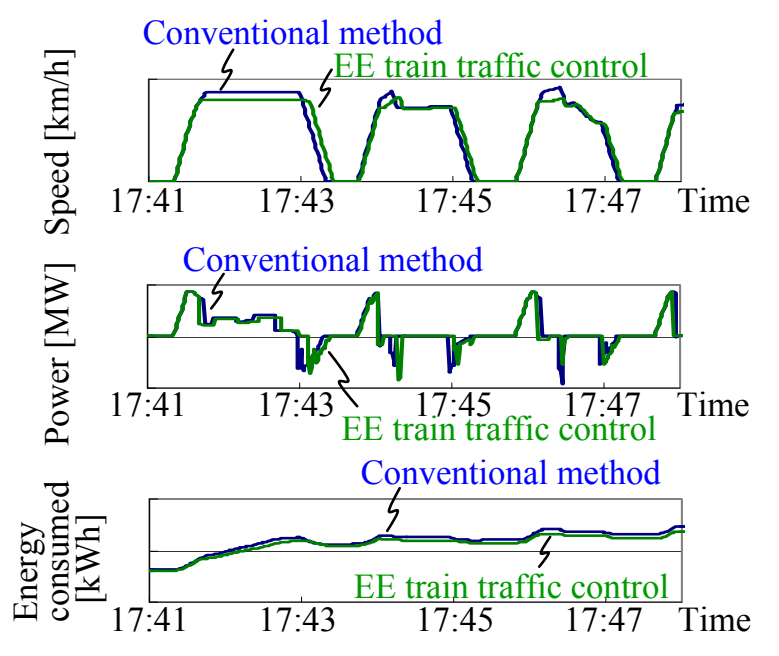

Figure 8: $\quad$ Simulation results (enlargements).

\subsection{The simulation results of a commuter line}

Similarly, the computer simulation for a commuter line at the following three kinds for adjustment time was carried out and compared. One is having no adjustment time (present) and the others are adjustment time of an average of 5 seconds (practical value) and an average of 10 seconds (maximum).

Table 2 shows the energy-consumed reduction effect of EE train traffic control.

Table 2: $\quad$ The reduction effect of the energy consumed by EE train traffic control.

\begin{tabular}{|c|c|c|c|c|}
\hline Case NO. & Route & $\begin{array}{c}\text { Adjustment } \\
\text { time }[\mathrm{s}]\end{array}$ & $\begin{array}{c}\text { Energy consumed } \\
{[\mathrm{kWh}]}\end{array}$ & $\begin{array}{c}\text { Decreasing } \\
\text { rate [\%] }\end{array}$ \\
\hline Case A1 & Subway & 0 & 11802 & - \\
\cline { 3 - 5 } Case A2 & & 4 & 11606 & $\begin{array}{c}1.7^{*} \\
3.4^{* *}\end{array}$ \\
\cline { 3 - 5 } Case B1 & \multirow{2}{*}{$\begin{array}{c}\text { Commuter } \\
\text { line }\end{array}$} & 0 & 3687 & - \\
\cline { 1 - 3 } Case B2 & & 5 & 3344 & 9.3 \\
\hline Case B3 & & 10 & 3090 & 16.2 \\
\hline
\end{tabular}

*In the case where the proposed system is applied only to a down line.

**The estimation value in the case where the proposed system is applied to an up-and-down line. 


\section{Consideration}

\subsection{Consideration of the difference in the rate of energy reducing consumption}

In railways, the difference among systems of a railway subsystem, such as the running speed of a train, operating method and operation interval, stoppage time, the vehicles' characteristics, regeneration vehicles introduction rate, and a feeding system, is great. In order to evaluate the usefulness of the proposed train traffic control system, typical two cases - a subway as case A and a commuter line as case B - were chosen and simulation examinations were carried out this time.

In the case of practical adjustment time, set up based on the operation timetable actually used, the reduction rate of the energy consumed by EE train traffic control was $3.4-16.2 \%$ in the simulation result. As one of the main things, although it is thought that there are various things, such as a difference in the characteristics of the above-mentioned object system, in the factor of a difference of the value of this reduction rate, the operating method of a train which rises to the next is mentioned.

Type A: Operation which combined the uniform run and the coasting.

Type B: The typical run as an operating method of the local train of the commuter line based on coasting.

By Type A, there is the section which is carrying out uniform operation and it is thought that the loss seldom reduced uniform operation in order to continue taking current, even if it lowers speed. The difference in such an operating method is considered to be the factor which fluctuated the energy consumed in the substation.

\subsection{Evaluation by the route characteristic}

The argument to the above was evaluation of the rate of energy reducing consumption at the time of adopting the control system to propose as the specific time zone considered to use it. In fact, an employable time zone is restricted by the route. Then, the reduction rate of the energy consumed in every year is presumed by the following premises, and the amount of energy saving is calculated.

1) Setup of EE train traffic control hour of use

Table 3 expresses the time zone which gets down and uses EE train traffic control during one day at a starting station, and the number of full time used for trial calculation. The simplification for calculation was performed in part.

2) Trial calculation of the annual rate of energy reducing consumption

In making the trial calculation of the annual rate of energy reducing consumption, a model is made with the following parameters. 
K1: The rate in which the energy reducing consumption there is no accident, wear and according to time adjustment is possible.

K2: The rate of the energy-saving effect of EE train operation control to the weekday of Saturdays-and-Sundays public holiday.

Table 3: $\quad$ Time zone of use of EE train traffic control.

\begin{tabular}{|c|c|c|c|c|}
\hline $\begin{array}{l}\text { Case } \\
\text { NO. }\end{array}$ & Route & $\begin{array}{l}\text { Adjustment } \\
\text { time }[\mathrm{s}]\end{array}$ & $\begin{array}{c}\text { Time zone of use of } \\
\text { EE train traffic control }\end{array}$ & hours $[\mathrm{h}]$ \\
\hline Case A1 & \multirow[t]{2}{*}{ Subway } & 0 & $7.00-9.00,17.00-19.00$ & 4 \\
\hline Case A2 & & 4 & $\begin{array}{c}6.00-7.00 \\
9.00-17.00,19.00-00.00\end{array}$ & 14 \\
\hline Case B1 & \multirow{3}{*}{$\begin{array}{l}\text { Commuter } \\
\text { route }\end{array}$} & 0 & $6.00-9: 30,16: 30-21.00$ & 8 \\
\hline Case B2 & & 5 & $9: 30-16: 30,21.00-00.00$ & 10 \\
\hline Case B3 & & 10 & $4.00-6.00$ & 2 \\
\hline
\end{tabular}

In addition, although cautions were required in the rush time zone and the offpeak time zone for the numbers of a diagram to differ, in this trial calculation, it was assumed that it was equivalent as a reduction rate. The rate of "weekday" and "Saturdays-and-Sundays public holiday" was set to 2:1.

The presumed result of the reduction rate of the energy consumed in every year is described in Table 4. The reduction rates of the energy consumed in every year can be presumed to be $2.2 \%$ of a subway, and $5.3 \%$ of a commuter line. Moreover, by subway, the amount of energy reduction in every year can be presumed to be $704 \mathrm{MWh}$, and can presume it to be $1643 \mathrm{MWh}$ in a commuter line.

Table 4: The reduction rate of the energy consumed in every year, the presumed result of the amount of reduction.

\begin{tabular}{|c|c|c|c|c|c|}
\hline $\begin{array}{c}\text { Case } \\
\text { NO. }\end{array}$ & $\begin{array}{c}\text { Route } \\
\text { conergy } \\
\text { consumed }\end{array}$ & Parameter & $\begin{array}{c}\text { Reduction } \\
\text { rate of } \\
\text { energy } \\
\text { consumed } \\
\text { per day[\%] }\end{array}$ & $\begin{array}{c}\text { Reduction } \\
\text { rate of } \\
\text { energy } \\
\text { consumed } \\
\text { per year } \\
{[\%]}\end{array}$ & $\begin{array}{c}\text { Reduction of } \\
\text { energy } \\
\text { consumed } \\
\text { [MWh/year] }\end{array}$ \\
\hline Case A & $\begin{array}{c}\text { Subway } \\
(32,000)\end{array}$ & $\begin{array}{c}\mathrm{k} 1: 0.8 \\
\mathrm{k} 2: 1.2\end{array}$ & 2.1 & 2.2 & 704 \\
\hline Case B & $\begin{array}{c}\text { Commuter } \\
\text { line } \\
(31,000)\end{array}$ & $\begin{array}{c}\mathrm{k} 1: 0.8 \\
\mathrm{k} 2: 1.2\end{array}$ & 5.0 & 5.3 & 1643 \\
\hline
\end{tabular}




\section{Conclusion}

In order to reduce the energy consumed in a railway system based on the grand design of the Railway EMS, the EE train traffic control system, which saves energy in connection with train operation, was developed. This is a method which controls the amount of the total use of energy in the range which maintains an operation timetable to a plan value.

In the case of commuter lines in the major cities of Japan, by carrying out EE train traffic control, the research results indicated a reduction of about $5 \%$ in energy consumption can be realized. Moreover, in the case of a subway, it turned out that a reduction of about $2 \%$ of energy consumption can be realized. In this trial calculation, the route with many rates of a uniform run was chosen in the subway, and the commuter line is based on the coasting. The fixed effect has been confirmed although there was a difference in the size of the effect of EE train operation control scheme by the difference in the operating method of a train, an operation interval, the vehicles' characteristics, etc.

Effective use of regeneration electric power is raised with a railway system as a subject of energy saving. In the short high-density route between stations, many trains have repeated acceleration and a deceleration and it is thought also in a route with many rates of vehicles with the function of a regenerating brake that electric power accommodation between trains is performed. Optimization of the timing of train traffic operation would be useful in the future.

Moreover, taking account of the information of signaling function into the train traffic control would be efficient for saving energy. It is also possible to build with new information transmission and control forms, such as Cloud, when introducing.

From now on, also paying attention to the energy optimal employment by cooperation accommodation with a general electric power system, utilization of the EMS function of the whole railway system will be promoted.

\section{References}

[1] H. Ko, T. Koseki and M. Miyatake, Application of Dynamic Programming to Optimal Running Profile of Train, COMPRAIL 2004, Germany, 2004.

[2] Lagos Mario, CATO offers energy savings, Railw. Gaz. In., Vol.167, No.5, pp. 50-52, 2011.

[3] Y. Mugiya, T. Takeba, Y. Kamo, K. Otsuji, K. Tanomura, M. Miyoshi, Energy Management and Control in Railway System (Part 1: Grand Design), IEE Japan, National Conference, 5-082, 2012.

[4] M. Miyoshi, T. Takeba, M. Miyatake, Energy Management and Control in Railway System (Part 2: Energy Efficiency Traffic Control), IEE Japan, National Conference, 5-083, 2012.

[5] T. Sekine, K. Imamura, M. Akashi, H. Tomikawa, Y. Takagi, Y. Mugiya, Examination of the summer power reduction in a railway, Japan Railway Engineers' Association, 48 ${ }^{\text {th }}$ Symposium of Railway Cybernetics, 2011. 